\title{
O jogo apolíneo-dionisíaco: aspectos filosóficos do esporte
}

\section{The Apollonian-Dionysian game: philosophical aspects of sport}

Marcos N. Beccari ${ }^{1}$,Daniel B. Portugal² e Rogério de Almeida ${ }^{3}$ pela Universidade de São Paulo (USP). E-mail: marcosbeccari@ufpr.br. Comunicação e Cultura pela Universidade Federal do Rio de Janeiro (UFRJ). E-mail: dportugal@esdi.uerj.br. 


\section{Resumo}

Este ensaio propõe uma reflexão acerca dos aspectos filosóficos do esporte, especialmente a partir das figuras míticas de Apolo e Dioniso. De início, a questão é colocada a partir de algumas campanhas publicitárias da Nike; em seguida, o aspecto apolíneo é associado aos ideais ascéticos seculares, ao passo que a dimensão dionisíaca é descrita como sombra que subsiste na celebração esportiva. Por fim, recorremos à figura homérica de Ulisses para entrelaçar Apolo e Dioniso, conjugando-os como faces complementares de uma mesma matriz de convivência sociocultural.

Palavras-chave

Jogos, filosofia, publicidade, ética.

\section{Abstract}

This essay proposes a reflection on the philosophical aspects of the sport, especially from the mythical figures of Apollo and Dionysus. Initially, we pose the question from some Nike advertising campaigns; then, we associate the Apollonian aspect with secular ascetic ideals, while we describe the Dionysian dimension as a shadow that subsists in sporting celebration. Finally, we turn to the Homeric figure of Ulysses to entangle Apollo and Dionysus, combining them as complementary faces of the same sociocultural matrix of coexistence.

\section{Keywords}

Games, philosophy, advertising, ethics. 


\section{Introdução}

A palavra "esporte" nos lembra, etimologicamente, de que sua origem está ligada à recreação, ao prazer. Desporto, outro termo equivalente a esporte, vem do francês desporter, divertir-se, distrair-se, jogar. Em certo sentido, pode ser compreendido como o que "retira", o que tira do lugar, o que sai do "porto" (des-porto), portanto, o que está fora do centro, da esfera mercadológica ou da seriedade da vida.

No entanto, a história recente tem mostrado que o esporte se tornou um setor da vida econômica, sendo consumido na forma de espetáculo. Com a transformação do esporte em evento midiático, sua prática vem se ajustando em função das exigências e necessidades desse meio. O resultado é a profissionalização do esporte, cuja evolução segue o vetor unilateral da lógica dinheiro-desempenho (MANSKE, 2013). Não se trata mais de mera diversão ou competição, mas de um negócio que pode ser muito lucrativo, seja para o atleta que se destaca, seja para todo o aparato que gravita em torno dele, investe nele e, de acordo com os resultados, lucra com seu desempenho, tal qual a aplicação em ações na bolsa de valores ou uma aposta na casa de jogos. Vaz (2005, p. 25) reitera o caráter superlativo que o esporte vem assumindo na cultura contemporânea, em que a "ilimitada ultrapassagem de limites" se alinha cada vez mais aos parâmetros dos consumidores esportivos, alimentando, assim, o imperativo da superação dos extremos por parte dos atletas.

Mas essa dimensão mais visível da prática esportiva e, mais especificamente, dos seus usos sociais, midiáticos e econômicos não encerra todo o esporte (ROSE, 2013). Neste artigo, buscamos justamente refletir sobre diferentes aspectos filosóficos que permeiam, hoje, a prática esportiva. Recorremos às pulsões do apolíneo e do dionisíaco, tal como concebidas por Nietzsche (2007), para evidenciar algumas de suas complexidades e de seus direcionamentos antitéticos ${ }^{4}$. 
Se, de maneira geral, essa prática tem sido frequentemente associada ao registro apolíneo do retorno dos ideais ascéticos, ainda resta, em latência, a sombra de Dioniso, que continua injetando nas práticas esportivas - sejam as que praticamos na hora de lazer, sejam as dos profissionais, devida ou indevidamente espetacularizadas uma forte carga de errância, de acaso, de crueldade e de alegria.

\section{Uma questão de grandeza?}

Não é de hoje que empresas esportivas reforçam, em suas campanhas publicitárias, valores ligados ao esforço, ao suor, ao treino duro, à disputa, à vitória, à performance. Ao mesmo tempo, há valores menos austeros aos quais tais marcas buscam se vincular. No começo dos anos 1960, por exemplo, um dos comerciais mais difundidos da Lucky Strike, marca de cigarros, era protagonizado por estrelas do beisebol e trazia o slogan: "Lucky Strike separa os homens dos garotos..., mas não das garotas" (BRANDT, 2007, p. 78, tradução nossa). O consumo esportivo, afinal, não se restringe aos rigores do esporte, tendendo a apresentá-lo com um tom descompromissado, divertido e, não raro, também erótico.

Em 2012, uma campanha publicitária internacional da Nike traz o slogan "Find your greatness" ("encontre sua grandeza"). Com diversos vídeos e peças impressas ${ }^{5}$, a campanha gira em torno de dois imperativos: 1) a grandeza não é algo exclusivo de pessoas especiais ou famosas; 2) a conquista da grandeza não depende da sorte ou do destino, mas do esforço e do treino. Algumas peças destacam a dimensão dolorosa dessa grandeza, como o vídeo que mostra uma jogadora de polo aquático em briga desesperada pela bola, enquanto sua voz em off pergunta: "É pela grandeza que estou lutando?". Ao fim da jogada, que resulta em gol, a vemos emergir da água e encarar a câmera com um olhar sereno e decidido. De seu nariz escorre sangue. Ao mesmo tempo, escutamos a resposta: "o que você acha?". Outras peças, porém, apontam para uma dimensão divertida da grandeza em questão. É o caso de um vídeo que mostra um rapaz fazendo 
malabarismos com bolas de basquete. Ouvimos em off a seguinte narração: "Algumas vezes, grandeza é sobre superar enormes adversidades. Às vezes, é apenas diversão"6.

O tom descontraído dessa peça em particular parece direcionar-se aos consumidores comuns, cuja prática amadora se aproxima mais da diversão do que da disciplina árdua dos atletas profissionais. A distância entre esses polos dilui-se ainda mais em outra campanha da Nike, de 2014, cujo slogan é "risk everything" ("arrisque tudo"). Em especial, no vídeo The Last Game7, uma animação de 5 minutos e meio, em que um vilão cria clones que jogam futebol de forma tecnicamente perfeita, mas sem estilo e criatividade. Como resultado, os grandes jogadores perdem lugar aos clones, sinalizando o fim do "futebol arte". Ronaldo Fenômeno, ou Ronaldinho - jogador extremamente famoso à época -, porém, reúne uma espécie de time dos sonhos com os melhores jogadores de todo o mundo, com o objetivo de derrotar os clones. O time não acredita que os clones podem ser vencidos, mas Ronaldinho os motiva com o seguinte discurso: "Lembrem-se do que torna vocês grandiosos. Vocês não têm medo de correr riscos. Vocês jogam como se isso fosse apenas um jogo [like it is just a game], eles jogam como se isso fosse um trabalho [like it is a job]. Vocês arriscam tudo para vencer".

Aqui, jogar como se fosse "just a game" não se opõe a jogar com "fome de vitória". Os jogadores, afinal, estão furiosos com a situação e pretendem arriscar tudo para vencer. O "just a game" opõe-se a jogar de maneira burocrática: tecnicamente perfeita, mas sem estilo. É a dimensão do maravilhoso e do glorioso que se perde quando o futebol se transforma em uma espécie de disputa puramente técnica. Assim, o "risk everything" se opõe à lógica do risco calculado mais ou menos do mesmo modo que a liberdade e a honra do cavaleiro se opõem à falta de sentido da guerra em tanques no romance Gläserne Bienen (Abelhas de vidro, sem tradução em português), de Ernst Jünger (1960). 
Finalmente, na campanha mais recente da Nike, lançada globalmente em 2021, é o dionisíaco que ganha preponderância. O slogan da campanha é "play new" ("vai no novo") e busca exaltar os "tropeços" dos iniciantes. O único vídeo da campanha disponível no momento da escrita deste artigo é uma compilação de cenas de péssimo desempenho esportivo, como a de uma tacada de golfe que atinge a grama em vez da bola ou um arremesso que sai do contexto do jogo para quebrar a vidraça de uma casa qualquer ${ }^{8}$. Essas cenas acompanham a seguinte narração em off: "Quer saber? Um brinde para quem tenta e manda mal. E para quem continua tentando, mesmo que a jogada seja um lixo. [...] A quem dá tudo de si, mesmo mandando mal. Porque você sabe o que não é nada mal? Tentar alguma coisa pela primeira vez". Aqui, portanto, o valor de destaque é a abertura ao novo, a novas experiências, ao prazer do jogo. O doar-se ao máximo passa a figurar como antípoda da obsessão apolínea pelo desempenho.

O que isso revela é a persistência, ao menos a nível de discurso (voltado ao consumo), do significado original de desporter, ligado à diversão e ao prazer. Entretanto, campanhas publicitárias fornecem-nos apenas indícios imprecisos de um imaginário mais complexo, cerceado de contendas interpretativas. Na leitura de Michel Maffesoli (2005), por exemplo, que vê na contemporaneidade o ressurgimento de Dioniso, ou ao menos sua sombra, o esporte une-se a uma série de outras práticas que atestam o prazer de estar junto, a vida sem finalidade, o êxtase coletivo, enfim, práticas dionisíacas. Em contrapartida, Gilles Lipovetsky (2007, p. 275) denuncia um hedonismo sistemático que calcula os riscos e exalta a performance, seja no esporte, no trabalho, no lazer ou até no sexo, manifestando "um novo narcisismo obcecado por recordes, músculos, rivalidades anatômicas". Seja como for, claro está que a celebração, a competição e a autossuperação são facetas que, no âmbito de uma abordagem mais filosófica do tema, merecem um recuo teórico. 


\section{A tensão vertical apolínea}

Segundo Giorgio Colli (1992), havia na origem da filosofia duas inclinações distintas para a formação do conhecimento: a de Apolo, que se manifesta na palavra (como em Delfos, com o deus falando por meio da sacerdotisa), e a de Dioniso, relacionada à divindade eleusiana ${ }^{9}$, cuja iniciação nos seus mistérios culminava na epopteia (BRANDÃO, 1986), ou seja, na visão mística do júbilo e da purificação. O primeiro tipo de conhecimento deve ser cultivado e depende da lógica, do trato das ideias, do exercício constante e consciente. O segundo tipo é revelação, clarividência, brota de forma misteriosa e testemunha uma alegria sempre injustificada.

A disseminação da filosofia escrita, a partir de Platão, assinala a preponderância apolínea no pensamento ocidental. No registro platônico, a busca pela superação, vitória, honra, glória, reconhecimento etc. ligava-se à parte da alma que os gregos denominavam Thymós, normalmente traduzida por "ira". O filósofo contemporâneo Peter Sloterdijk (2014), que nas últimas décadas tem investigado a dimensão thymótica, a associa a uma "tensão vertical" que exige do indivíduo um esforço ascético, isto é, que o faça superar um estado dado em proveito de uma grandeza latente, ainda não alcançada.

Não é por acaso que Sloterdijk toma Nietzsche como ponto de partida, já que este, em sua Genealogia da moral, apresentou a ascese como base de todas as culturas religiosas e suas condutas morais. Para Sloterdijk, os ideais ascéticos retornam na virada do século XIX para o XX não mais como uma nova religiosidade, mas, pelo contrário, como valorização desespiritualizada do corpo humano. O atletismo, sob o pretexto da restauração do olimpismo da antiguidade, reativa o asceta, que, liberado de qualquer contexto transcendental, tenta superar a si mesmo ao competir com outros atletas envolvidos no mesmo projeto de autossuperação. O campo do consumo esportivo, como vimos, possui um motor thymótico bastante evidente. É assim que Sloterdijk responde à indagação 
nietzscheana, no final da Genealogia, sobre quais valores seriam capazes de orientar a vida depois do crepúsculo dos deuses:

A vitalidade, entendida somaticamente e espiritualmente, é mesmo o meio que contém um desnível entre o mais e o menos. Ela tem dentro de si o movimento vertical que orienta as subidas, ela não precisa adicionalmente de atratores externos e metafísicos. Que Deus deve estar morto, neste contexto, não importa. Com ou sem Deus cada um chega somente tão longe quanto a sua forma física permite. (SLOTERDIJK, 2014, p. 67, tradução nossa)

Trata-se, como resume o título do livro supracitado, do imperativo "Você tem que mudar sua vida!", cuja expressão Sloterdijk empresta, não por acaso, de um verso de Rilke no poema "Torso arcaico de Apolo". A tensão vertical que assim se expressa possui uma dimensão ético-pedagógica. Ética porque estabelece uma hierarquia entre valores; pedagógica porque implica perseguir algo mais alto que já estaria, de forma embrionária, contido na alma e no corpo do discípulo. De acordo com o filósofo, ademais, a pedagogia europeia sempre oscilou entre dois extremos: o adestramento autoritário e o antiautoritarismo libertário. Entre um e outro, a tensão vertical é garantida nos exercícios de disciplinamento individual, com base em exigências internalizadas e no autoexame regular (práticas endoretóricas):

Todos os exercícios, sejam eles de natureza yoga, atlética, filosófica ou musical, somente podem acontecer se suportados por processos endoretóricos, nos quais atos da autoexortação, do autoexame e da autoavaliação, sob os critérios da tradição escolar específica e sob apontamento contínuo na direção dos mestres que já alcançaram o objetivo, têm um papel decisivo. (SLOTERDIJK, 2014, p. 369, tradução nossa)

Desse modo, torna-se compreensível que o não cuidado com o corpo ou com a saúde seja frequentemente visto, na atualidade, como inadimplência consigo mesmo. No entanto, esse desvio costuma ser imputado não tanto a uma vontade fraca, má ou pecaminosa, mas sim a algo da ordem da doença: 
baixa autoestima, depressão, déficit de atenção. A "medicalização da moral", contudo, não fecha necessariamente as portas para a autossuperação.

\title{
A reversibilidade da fonte dionisíaca
}

O esporte, sobretudo o de alto desempenho, parece ser todo apolíneo, já que depende de treinamentos repetitivos, de controle emocional, de uma execução tecnicamente correta nas competições, enfim, de um autodomínio do atleta, consciente de suas ações e decisões. Ocorre que os exercícios mais árduos não deixam de guardar uma forte relação com um prazer sensual, desordenado, de difícil explicação. Se uma medalha de ouro pode ser explicada como a coroação de anos, décadas de treinamentos intensos, como explicar a alegria não da vitória, autojustificada, mas a que provém do dia a dia de treinamento, misturada à dor dos exercícios físicos?

Em poucas palavras, por mais que Apolo presida a plasticidade da ascese thymótica, sua intensidade vertical, sua tensão, o que permanece no fundo, alimentando o fluxo desse impulso, talvez seja uma fonte dionisíaca, que pode ser traduzida como uma espécie de alegria, gozo, prazer, mas que é também cruel, obsessiva, maníaca.

\begin{abstract}
A experiência dionisíaca, [...] em vez de autoconsciência, significa uma desintegração do eu, que é superficial, e uma emoção que abole a subjetividade até o total esquecimento de si; em vez de medida é a eclosão da hybris, da desmesura [...] é um comportamento marcado por um êxtase, um enfeitiçamento, uma extravagância de frenesi sexual que destrói a família, por uma bestialidade natural constituída de volúpia e crueldade, de força grotesca e brutal; em vez de sonho, visão onírica, é embriaguez, experiência orgiástica. (MACHADO, 2017, p. 31-32)
\end{abstract}

Nietzsche (2007) diferencia a força apolínea, fundada na consciência e no autodomínio, da força dionisíaca, responsável pela sensualidade, crueldade e desordem. Só que seu Dioniso vai além, já que subsidia a inversão ou transvaloração de todos os valores, como propõe sua filosofia madura. Antes de esclarecermos esse ponto, porém, cumpre observarmos mais detidamente alguns contornos míticos de Dioniso. 
Dioniso é o deus que nasce duas vezes, a primeira do ventre de Sêmele, que não termina sua gestação, e a segunda da coxa de Zeus (BRANDÃO, 1987). David Lima (2012), recontando o mito de Dioniso, nos lembra que, em uma das versões, Hera enviou figuras gigantescas para assustá-lo, logo após seu nascimento. Essas figuras, com os rostos esbranquiçados, não conseguem, porém, assustar a criança, que permanece centrada, em pleno equilíbrio. Tentam, então, desviar sua atenção com piões coloridos, ossinhos barulhentos, outros brinquedos, mas não conseguem nenhum efeito. Até que oferecem ao pequeno Zagreu um espelho. Defrontando-se com sua própria imagem refletida, fica fascinado. Preso a ela, perde-se e, vulnerável, é atacado e morto pelos gigantes titânicos, que o devoram.

Sabemos que Dioniso será gestado, pela segunda vez, na coxa de Zeus, tendo seu segundo nascimento e sua coroação divina. Mas é importante reter que ele não teria sido devorado se não tivesse visto a sua própria imagem no espelho.

De modo análogo, isto ocorre com muitos atletas que ainda não estão preparados para cumprir a tarefa. Acham-se mais do que são, tornamse extremamente inflados pelo próprio deslumbramento, perdem-se na fama e na enorme quantidade de dinheiro que recebem em pouco tempo. Poucos são os que conseguem equilibrar-se entre o ser e o ter. Passam a ter e deixam de ser. (LIMA, 2012, p. 43)

A mesma metáfora vale para o esporte como um todo, já que é ao se olhar no espelho, ao se deixar seduzir pela espetacularização em torno de sua prática, que sua alma se perde, que seu sentido celebratório se suspende, que sua alegria inebriante se subordina à frieza meticulosa das aferições de desempenho ou lucro. No âmbito individual do atleta, o deslumbramento dionisíaco é o preço a ser pago pela mais alta ascese thymótica: o santo não pode saber que é santo. Mas quem além do excepcional, afinal, seria capaz de reconhecer plenamente o excepcional?

Eis a reversibilidade de Dioniso: sua dilaceração é promessa de renascimento. Ao passo que "Apolo atrai o homem para a envolvente rede do enigma, Dioniso o enreda - num jogo inebriante - nos meandros do Labirinto" (COLLI, 1992, p. 26), 
de modo que "o jogo se transforma em trágico desafio, em perigo do qual se podem salvar, mas sem arrogância, o sábio e o herói" (p. 26). De acordo com Junito Brandão (1987, p. 140), com efeito, "Dioniso retrataria as forças de dissolução da personalidade: a regressão às forças caóticas e primordiais da vida".

Trata-se de renascer, revigorar-se, perdendo-se a si mesmo. Junto da crueldade há o prazer voluptuoso de usufruir da própria queda; sua potência de vida é, a um só tempo, atraente e assustadora, mistura de furor e alegria, sabedoria e embriaguez. Daí que Nietzsche (2007) associa a paixão de Dioniso ao nascimento da tragédia, ligando-o à música para melhor afirmar a natureza de sua potência. A faculdade dionisíaca é uma faculdade criadora, é loucura e harmonia. Dito de outra forma, pensar o pior da existência é parte do exercício de aprovação dessa mesma existência. Aprovação que é sinônimo de alegria. E aqui é preciso entender que essa alegria não expressa um valor, mas sim uma transvaloração dos valores que leva a um conhecimento trágico (ou dionisíaco).

Sem dúvida Nietzsche sempre se valeu de Dioniso, deus do vinho e da embriaguez. Mas o Dioniso de Nietzsche é também o deus do mais profundo e lúcido conhecimento, associando sempre ao calor da embriaguez a fria sobriedade do saber [...]. A beatitude nietzscheana é mesmo uma embriaguez, mas não uma embriaguez que permitisse se livrar do saber, de não levar em conta o que o saber pode ter de lamentável e de deletério, ao modo da diversão pascaliana. Muito pelo contrário: ela é o que dá acesso ao saber, o que autoriza o saber pleno (e é a única a autorizá-lo). Pois não há saber sério que seja aceitável conscientemente sem a autorização de uma beatitude absoluta, a qual, não pondo condição alguma ao exercício da felicidade, não impõe - e é a única a não impor limitação alguma ao exercício do saber. É nisso que a alegria nietzscheana é necessariamente sábia, ou "sabente", por se medir com a amplitude do que lhe é permitido conhecer sem dano; e, reciprocamente, que o saber nietzscheano é necessariamente alegre, por só existir em proporção da alegria que o torna possível. (ROSSET, 2000, p. 66-67)

Esse pensamento de aprovação não põe o seu acento na "verdade", na "regra", na "justiça", mas na alegria injustificável e misteriosa da vida, do pensamento e, por extensão, da prática esportiva, sempre que esta se processa de maneira celebratória. Não se trata de confundir o esporte com distração, lazer, 
ou mesmo com a diversão de Pascal, por meio da qual nos livramos da gravidade das ações produtivas e dos pensamentos desagradáveis; trata-se justamente de negar a oposição entre os termos. Nesse sentido, uma filosofia da vida que primasse pela alegria da aprovação, alegria dionisíaca, se expressaria tanto por uma gaia ciência quanto pela celebração esportiva, incluindo também a ascese apolínea. Tal sorte de transfiguração antinômica, ademais, encontra-se desde O nascimento da tragédia, conforme sintetiza Roberto Machado:

Concebendo os dois instintos fundamentais da natureza, o apolíneo e o dionisíaco, respectivamente como aparência e essência, a importância da reflexão filosófica de Nietzsche nesse momento se evidencia na tese de que a arte trágica possibilita uma experiência estética do mundo de onde está totalmente ausente a oposição metafísica de valores: na tragédia, Apolo atrai a verdade dionisíaca para o mundo da bela aparência; Dioniso fala a linguagem de Apolo; Apolo, a linguagem de Dioniso. A "hipótese metafísica" formulada por Nietzsche é que o ser verdadeiro tem necessidade da bela aparência; que a verdade tem um desejo originário de aparência; que "a vontade queria se ver transfigurada em obra de arte" [...]. (MACHADO, 2017, p. 143)

\section{Considerações finais}

O fenômeno esportivo, tanto no registro profissional quanto no amador e de consumo, pauta-se numa inegável "tensão vertical", nos termos de Sloterdijk, que atesta a sobrevida de ideais ascéticos num mundo desespiritualizado. Enquanto o "ascetismo de diversas escolas espirituais alimenta-se dessa esperança, estendendo a elevação pelo exercício até a tentativa de alcançar, seguindo a atração sentida pela tensão vertical, o divino" (BRÜSEKE, 2011, p. 169), na atualidade tais ideais delineiam um processo duro e violento de constituição subjetiva, a sustentação de uma identidade clara, bem definida, funcional, uma identidade que aprendeu a se dobrar às imposições do trabalho e da eficiência. Mas assim como ilustra o comercial da Nike "The Last Game", em que vencer a todo custo não se opõe ao estilo e à criatividade, a ascese vertical que baliza o esporte contém um elemento essencial de prazer, ligado ao êxtase dionisíaco da dissolução dos limites e do próprio eu. 
Reconhecer essa polimorfia simultaneamente cruel e prazerosa, que solapa as bases do disciplinamento vertical, não implica nenhuma novidade. Foi uma percepção central, por exemplo, de pensadores como Adorno e Horkheimer (2006), que interpretam o confronto de Ulisses contra o Ciclope Polifemo - o herói da Odisseia passa-se por "ninguém", oferece vinho ao monstro para embriagá-lo, fura seu único olho e finge-se de morto para escapar - como recalque social do pensamento esclarecido. Sua tese é que a Aufklärung, a civilização iluminista, tem horror às práticas mágico-miméticas, que fazem ressurgir essa ameaça imemorial do prazer ligado à dissolução dos limites claros e fixos do ego. São as tendências dionisíacas (ou a "parte maldita") que nos ligam ao animal, ao barro, à sujeira, mas também à gratuidade e ao desperdício erótico e lúdico - como tematiza, por exemplo, toda a obra de Georges Bataille (2013). Conforme sintetiza Giorgio Colli,

A figura de Dioniso, com efeito, perfaz uma dimensão do esporte que, por mais negligenciada que seja, por mais invisível que possa parecer, está presente em muitas camadas da atividade esportiva. Podemos então considerar, nesse sentido, que a esfera dionisíaca do esporte - e reiteramos que esta é apenas uma faceta, a que está na sombra (MAFFESOLI, 2005) - agencia uma sabedoria trágica que orienta a vida para a experiência da aprovação e que estaria na base da celebração da vida. Na esteira de Nietzsche, trata-se de assumir uma postura artística diante da vida ou, nos termos de Roberto Machado (2017, p. 149-150), de "considerar a arte trágica como modelo de um pensamento e uma atividade que, não mais dominados pela vontade de saber, expressem uma vontade afirmativa de potência".

Cabe-nos ainda salientar, contudo, que tanto a dimensão dionisíaca quanto a apolínea não parecem ser suficientes para explicar filosoficamente o esporte como 
elemento intrínseco à cultura, para além da celebração e do ímpeto competitivo. Para esboçar uma interpretação nesse sentido, e na tentativa de amarrar provisoriamente os contornos dionisíacos aos apolíneos, recorremos à imagem de Ulisses, cuja Odisseia para voltar a Ítaca é uma luta heroica contra monstros e outros seres fabulosos e, ao mesmo tempo, a perdição nesse mundo mítico, simultaneamente aterrorizante e sedutor. Mais do que isso, como sublinha Jeanne Marie Gagnebin (2006, p. 21), a Odisseia acena para uma definição plural da cultura humana: "a capacidade de entrar em relação com o outro sob suas diversas formas".

De um lado, Ulisses representa a própria narrativa olímpica que confere à competição a metáfora das batalhas, a ideia de luta, com os atletas alçados à condição de heróis, representantes de uma equipe, cidade ou país. De outro, trata-se de adentrar o território desconhecido das ilhas míticas para, pouco a pouco, depois de perder-se muitas vezes, chegar ao mundo reconquistado da condição humana. Mas o que seria essa condição? De saída, é o que resguarda Ulisses contra a dupla sedução do inumano: a de tornar-se animal, como alguns de seus companheiros, transformados em porcos por Circe, e a de tornar-se divino, como Calipso oferece a Ulisses, que recusa a oferta. Essa é a ambiguidade secreta, mas central, tanto de Ulisses quanto do esporte. Apolo e Dioniso, divino e animal, são as duas faces complementares de uma mesma condição vital: a que nos faz mortais.

\section{Referências}

ADORNO. T. W.; HORKHEIMER, M. Dialética do esclarecimento. Rio de Janeiro: Jorge Zahar Editor, 2006.

BATAILLE, G. A parte maldita. Belo Horizonte: Autêntica, 2013. 
BECCARI, M.; PORTUGAL, D. B.; SALGADO, J. Seja estúpido: o imperativo trágico da Diesel e o ethos contemporânea. Esferas, Brasília, DF, v. 1, n. 2, p. 19-29, 2013.

BRANDÃO, J. Mitologia Grega. Petrópolis: Vozes, 1986. v. 1.

BRANDÃO, J. Mitologia Grega. Petrópolis: Vozes, 1987. v. 2.

BRANDT, A. The Cigarette Century: the rise, fall, and deadly persistence of the product that defined America. New York: Basic Books. 2007.

BRÜSEKE, F. J. Uma vida de exercícios: a antropotécnica de Peter Sloterdijk. Revista Brasileira de Ciências Sociais, São Paulo, v. 26, n. 5, p. 163-174, 2011.

COLLI, G. O nascimento da filosofia. Campinas: Editora da Unicamp, 1992.

GAGNEBIN, J. M. Lembrar escrever esquecer. São Paulo: Editora 34, 2006.

JÜNGER, E. The Glass Bees. New York: Nyrb, 1960.

LIMA, D. A. S. Técnico-mestre e atleta-herói: uma leitura simbólica dos mitos de Quíron e do herói entre técnicos de voleibol. 2012. Dissertação (Mestrado em Educação Física) - Universidade de São Paulo, São Paulo, 2012.

LIPOVETSKY, G. A felicidade paradoxal. São Paulo: Companhia das Letras, 2007.

MACHADO, R. Nietzsche e a verdade. São Paulo: Paz e Terra, 2017.

MAFFESOLI, M. A sombra de Dioniso: contribuição a uma sociologia da orgia. São Paulo: Zouk, 2005. 
MANSKE, G. S. Atletas do século XXI: ou das fusões biotecnológicas nos atletas de alto rendimento. Movimento, Porto Alegre, v. 19, n. 1, p. 289-308, 2013.

NIETZSCHE, F. O nascimento da tragédia ou helenismo e pessimismo. São Paulo: Companhia das Letras, 2007.

PORTUGAL, D. B.; SALGADO, J.; BECCARI, M. Um cisne, duas forças: sobre apolíneo e dionisíaco na ética do consumo. Psicologia Clínica, Rio de Janeiro, v. 26, n. 1, p. 17-31, 2014.

ROSE, N. A política da própria vida: biomedicina, poder e subjetividade no século XXI. São Paulo: Paulus, 2013.

ROSSET, C. Alegria: a força maior. Rio de Janeira: Relume-Dumará, 2000.

SLOTERDIJK, P. You must change your life. Malden: Polity Press, 2014.

VAZ, A. Doping, esporte, performance: notas sobre os "limites" do corpo. Revista Brasileira de Ciências do Esporte, Campinas, v. 27, n. 1, p. 23-36, 2005.

submetido em: 10 ago. 2021 | aprovado em: 30 set. 2021 